\title{
Preface to the special issue on the "COVID-19 and Education"
}

Welcome to this special issue titled "COVID-19 and Education" of Journal of Pedagogical Research. The COVID-19 Pandemic seriously affects life in all countries and causes changes that are likely to be permanent in the long term. Especially, the regular delivery of education and training has been impacted dramatically. According to the UNESCO (2020) Report, about one billion students worldwide are actually out of school. This situation has greatly accelerated the need of reinforcing the ability of educational institutions and schools to provide effective online teaching. Thus, this special issue aims to share applications in various countries, to provide a better understanding of how online educational resources and digital platforms are adapted in e-learning progress, to examine advantages and the disadvantages of the implementations in different contexts, and to build alternative strategies on the existing facilities in times of Pandemic. The call for papers attracted many high-quality submissions from various countries.

The special issue contains a collection of six papers.

In our first paper of the special issue, "Teachers' experiences of stress and their coping strategies during COVID-19 induced distance teaching", Klapproth, Federkeil, Heinschke, and Jungmann explored teachers' experiences of stress during the lockdown of schools in Germany, their strategies to cope with it, and external and internal barriers for distance teaching with an online questionnaire. They found that the level of stress experienced by teachers was medium to high and more than half of all participating teachers spent more than four hours a day on remote teaching. The results of this study also confirm that the teachers in Germany applied on average more functional coping strategies than dysfunctional coping strategies. The study provides implications based on their results for effective remote teaching in pandemic times.

In "Challenges of higher education institutions against COVID-19: The case of Turkey", Karademir, Yaman, and Saatçioğlu identify the current situation in Turkey by examining the experiences and opinions of academics, distance education center managers, parents, and students. Following a phenomenological research design, they focus on the quality of distance education implementations in higher education in Turkey. The results of the study show that the pandemic had negative psychological effects on all stakeholders of higher education and distance education implementations suffered from infrastructural and psychological issues in Turkey. They provide actionable recommendations for national and international policymakers in light of the results of their study.

In the next paper, "Students' perceptions of using mobile technologies in informal English learning during the COVID-19 epidemic: A study in Chinese rural secondary schools", Guo, Huang, Lou, and Chen examine secondary school students' perceptions of mobile learning during the COVID-19 epidemic in the informal English learning context in China. This predictive quantitative study revealed that the students held positive attitudes towards mobile-assisted English learning, and their intentions were significantly influenced by perceived usefulness, facilitating conditions, and attitude towards the use of mobile devices. The paper provides a deeper insight into mobileassisted language learning theories by unpacking rural secondary school students' intentions to use mobile technologies in English learning. Moreover, the results of the study have significant implications for English teaching and learning, as well as teachers, educational administrators, and policymakers.

In the following paper, "Positive and negative affect during a pandemic: Mediating role of emotional regulation strategies", Kara and Gök examine the mediating role of emotional regulation strategies in the relationship between positive affect and negative affect experienced by individuals during 
the COVID-19 pandemic using mediation analysis. The study concludes that emotional regulation strategies have a mediator role in the association between positive affect and negative affect of individuals. Also, it reveals that negative affect significantly and negatively predicts the emotional regulation strategies of individuals. They emphasize the importance of mental health protection and emotional regulation strategies for people in the Covid-19 pandemic.

In "The Online and Campus $(\mathrm{OaC})$ model as a sustainable blended approach to teaching and learning in higher education: A response to COVID-19" Petronzi and Petronzi proposes a pedagogical model named Online and Campus Model based on their review of pertinent blended learning literature. This model identifies the need for a clear association and connection between campus, digital synchronous, and digital asynchronous approaches. They provide a sample half-semester module plan according to the OaC model approach.

In the last paper, "A narrative inquiry into the spatial experience: Learners' recollections from preCOVID-19 classroom setting", Çıraklı and Özbay explores the recollections of individual learners from the pre-COVID-19 classroom environment following their virtual learning environment experience following a thematic organization and evaluation model. They focus on the spatial experience and how it serves for the episodic (positive) active memory, mind, and imagination of the learners in Turkey. The results of the study highlight that the participants' small narratives are punctuated with references to setting elements and objects in the form of emotive spatial experience and positive episodic memories. The study presents the implications for applied linguistics and classroom research in times of Pandemic.

We hope that our readers enjoy this special issue.

\section{Reference}

UNESCO (2020). Education: From disruption to recovery. Accessed 12 December 2020. https://en.unesco.org/covid19/educationresponse/

Guest Editors

Dr. Mehmet Kokoç

Trabzon University, School of Applied Sciences

E-mail address: kokoc@trabzon.edu.tr

Dr. Zamzami Zainuddin

The University of Hong Kong E Sekolah Tinggi Ilmu Administrasi Nasional E-mail address: zamzami.hku@gmail.com 